\title{
Experience of Satellite Trackers' Application for Watching Glaciers in the Arctic
}

\author{
S. V. Motyzhev ${ }^{1} *$, A. P. Tolstosheev ${ }^{1}$, E. G. Lunev ${ }^{1}$, A. L. Salman ${ }^{2}$ \\ ${ }^{1}$ Marine Hydrophysical Institute, Russian Academy of Sciences, Sevastopol, Russian Federation \\ ${ }^{2}$ ES-PAS Ltd, Moscow, Russian Federation \\ *e-mail: smotyzhev@mail.ru
}

\begin{abstract}
The engineering and operational features of the satellite trackers iceST/40-Glacier developed in the Marine Hydrophysical Institute, Russian Academy of Sciences, and produced by Marlin-Yug Ltd are considered. The trackers are developed to monitor the glaciers' movements. The glaciers' motion characteristics are calculated using the tracker coordinates measured by the satellite GPS receiver and distributed among the users due to the worldwide location and data collection system Argos- 2 . The satellite tracker construction is simple enough to place it on a glacier. It represents a specially developed measurement algorithm that permits, first, to apply a standard low-cost GPS receiver and, second, to define location with accuracy not exceeding $1.7 \mathrm{~m}$. The measurements required to determine location are done once a week. The tracker lifetime is not less than 24 months. Statistical analysis of the long-term field experiments carried out on the Arctic archipelagos' glaciers results in drawing a conclusion that, the iceST/40-Glacier satellite trackers, being used as a basis, make creation of reliable, technological and low-cost network for regular monitoring the glaciers' movements possible and expedient. The information obtained due to such a network permits to increase navigation safety in the Arctic Ocean marginal seas and can be used for verifying remote sensing data.
\end{abstract}

Keywords: satellite tracker, determination of position, glacier movement, Arctic observations.

Acknowledgements. The work was carried out within the framework of the State Order No. 08272014-0011 "The research of regularities of marine environment condition changes on the basis of operational observations and the data of marine area condition nowcast, forecast and reanalysis system" ("Operative oceanography" code) with financial support of PAO OC Rosneft.

For citation: Motyzhev, S.V., Tolstosheev, A.P., Lunev, E.G. and Salman, A.L., 2018. Experience of Satellite Trackers' Application for Watching Glaciers in the Arctic. Physical Oceanography, [e-journal] 25(2), pp. 153-161. doi:10.22449/1573-160X-2018-2-153-161

DOI: $10.22449 / 1573-160 X-2018-2-153-161$

(C) 2018, S. V. Motyzhev, A. P. Tolstosheev, E. G. Lunev, A. L. Salman

(C) 2018, Physical Oceanography

Introduction. Economic activity in the polar regions is somehow related to the evolution of glaciers. Total area of glaciation of the Russian Federation Arctic zone islands is more than $56.000 \mathrm{sq}$. km [1]. Glaciers cover from 30 to $45 \%$ of the territories of Novaya Zemlya and Severnaya Zemlya archipelagos, from 57 to $90 \%$ of Spitsbergen and Franz Josef Land archipelagos. The adequacy of ideas about the movement of glaciers is crucial when making management decisions on environmental protection, adjusting existing and justifying future economic projects. The safety of navigation in the marginal seas of the Arctic Ocean is directly related to the reliability of information on the movement of ice-cover glaciers which produce icebergs [2]. The urgency of glacier monitoring problem is obvious, and its solution is impossible without the creation of a stable system of complex observations combining modern monitoring technologies. Remote methods (radar, optical, etc.) [3-5] are the main component of such a system, for sure. Modern satellite data processing algorithms, applied for glaciological studies, provide the reconstruction of 
glacier motion parameters with 10-15 m geometric resolution [5, 6]. However, taking into account low velocities of glacier movement (from several meters to hundreds of meters per year), this resolution allows us to diagnose either their shortterm abnormally high motions or small displacements during a long time. Reliability of remote monitoring results is determined by the capabilities of satellite data verification $[7,8]$. The absence of a correct network of sub-satellite control and calibration measurements is an objective obstacle in the development of remote glaciology methods. In addition, the systematic nature of the satellite data input largely depends on the weather conditions.

The problem of glacier dynamics operational monitoring is solved using field observations and the ones carried out with global positioning systems (GPS). The data obtained in this way is also used for the verification of satellite measurements. The method for reconstructing the motion parameters of the glacier from the coordinates of the GPS receiver installed on it has been applied in the practice of glaciology for a long time $[9,10]$. At the discrepancies comparable with the ones of field observations, the method provides the automation of data acquisition process and the appliance of modern satellite communication means ensures the prompt information delivery to the users.

In this work one of the options for implementing the mentioned method - satellite radio beacon iceST/40-Glacier, developed in Marine Hydrophysical Institute (MHI) of RAS, is considered. Radio beacons are manufactured by the Russian company Marlin-Yug Ltd. [11]. The necessity of such a development is explained by the fact that despite a wide (according to publications) range of gauges, Russian glaciology does not have a monitoring tool with acceptable performance characteristics which would provide high accuracy of coordinate measurements and high rate of data delivery to users with long-term autonomous operation, resistance to the impact of factors characteristic of the polar regions, simple deployment technology and low cost. Analyzing the current state of the problem, the authors of [12] point out that "the volume of ground-based observations significantly decreased, and they do not provide full information about the fluctuations of glaciers" (p. 365).

Design concept and operation principle of satellite radiobeacon iceST/40-Glacier. During the last fifteen years, the drifting tools for environmental observations that meet all of the abovementioned requirements are successfully developed in MHI. The technology for developing such tools was taken as a basis when creating iceST/40-Glacier radiobeacon. For measuring the beacon coordinates, the built-in GPS receiver UP501 (Fastrax) (URL: http://www.anglia.com/fastrax/datasheets/UP501.pdf [Accessed 20 September 2017]) is used. The choice of the receiver is based on long-term experience in the development and operation of autonomous data collection platforms and is explained by an acceptable combination of such characteristics as positioning error, power consumption and cost. The results of the measurements are transmitted via the communication channels of the system for satellite data acquisition and determination of platform coordinates Argos-2 [13]. Under the abovementioned algorithm of measurements and data transmission the capacity of the power supply elements of the radiobeacon provides its operability for at least 24 months. 
For assessing the real error in the coordinate measurements (a defining attribute of radiobeacon assignment), UP501 receiver tests were performed during the development process, in which statistical estimates of the results of coordinate measurements of a permanently installed receiver were studied. The long-term, up to 24 hours long, series of coordinates with $1 \mathrm{~Hz}$ frequency were used. Based on the test results, the following algorithm for the data processing and transmitting, minimizing the error in estimating the coordinates with regard to the energy consumption limitations and the data throughput of the satellite communication channel, was developed:

- every Sunday at 01:00 radiobeacon automatically switches from the standby mode to the operating one, which lasts till 22:00. In this mode the measuring, data processing and transmission are carried out;

- from 01:00 to 19:00 GPS receiver measures radiobeacon horizontal coordinates with $1 \mathrm{~Hz}$ frequency. Measurement results are filtered in the data processing unit. For filtering the service parameters $N S$ and HDOP are used, which accompany each measurement result: $N S$ - the number of satellites in the "visibility zone" of the receiver; $H D O P$ - the value of the accuracy index of the horizontal position determination. As a result of the filtering, only those coordinate samples for which $N S>4$ and $H D O P<2$ are used for subsequent processing;

- on each $k$-m measurement interval of 5 min duration, according to coordinate measurements satisfying the mentioned conditions the median latitude $\left(\varphi_{\mathrm{Me}}\right)_{k}$ and longitude $\left(\lambda_{\mathrm{Me}}\right)_{k}$ values are calculated. They are stored in the internal memory of the radiobeacon and for the next 5 minutes with $(90 \pm 9) \mathrm{s}$ interval are transmitted via the communication channel of satellite system Argos-2. Here k $=1 \ldots 215$ is the sequence number of each 5-minute interval in 01:00- 19:00 period;

- latitude $\left(\varphi_{N S_{\mathrm{m}}}\right)_{k}$ and longitude $\left(\lambda_{N S_{\mathrm{m}}}\right)_{k}$ measurements obtained at the greatest $N S$ values over each $5 \mathrm{~min}$ are also stored in the internal memory of the radiobeacon;

- at 19:00 the average daily coordinates for all median values $<\varphi_{\mathrm{Me}}>=\frac{1}{215} \sum_{k=1}^{215}\left(\varphi_{\mathrm{Me}}\right)_{k}, \quad<\lambda_{\mathrm{Me}}>=\frac{1}{215} \sum_{k=1}^{215}\left(\lambda_{\mathrm{Me}}\right)_{k}$ and for all coordinate measurements at the greatest values of $N S \quad-<\varphi_{N S_{\mathrm{m}}}>=\frac{1}{215} \sum_{k=1}^{215}\left(\varphi_{N S_{\mathrm{m}}}\right)_{k}$, $<\lambda_{N S_{\mathrm{m}}}>=\frac{1}{215} \sum_{k=1}^{215}\left(\lambda_{N S_{\mathrm{m}}}\right)_{k}$ are calculated, as well as the temperature of the radiobeacon body and power supply voltage are measured;

- from 19:01 to $22: 00$ daily average coordinates $\left.\left(<\varphi_{\mathrm{Me}}\right\rangle,\left\langle\lambda_{\mathrm{Me}}\right\rangle\right)$, $\left(<\varphi_{N S_{\mathrm{m}}}>,<\lambda_{N S_{\mathrm{m}}}>\right)$ and measured values of the radiobeacon body temperature and power supply voltage are transmitted via the communication channel of $\mathrm{Ar}$ gos -2 system.

The results of coordinate measurements of ID137954 radiobeacon provide quantitative assessment of the efficiency of such an algorithm for data processing and transmission under real operational conditions. The radiobeacon was installed 
on an ice-covered rocky peak, nunatak, on one of the islands of the Russian Federation Arctic Zone. The total duration of the radiobeacon operation as at May 21, 2017 was 743 days. During this period 106 weekly data blocks were received. This provided the statistically significant evaluation of the characteristics of the error in coordinate measurements and the quality of information transmission via the satellite communication channel.

Estimations of coordinate measurement errors. The following parameters were calculated as characteristics of coordinate measurement errors of ID137954 radiobeacon:

1) the distribution of deviations between the locations with daily average coordinates $\left.\left(<\varphi_{\mathrm{Me}}\right\rangle_{\mathrm{w}},\left\langle\lambda_{\mathrm{Me}}\right\rangle_{\mathrm{w}}\right)$ and the location with the mean over the entire observation period coordinates $\left.\varphi_{\mathrm{r}}=\frac{1}{N} \sum_{w=1}^{N}<\varphi_{\mathrm{Me}}\right\rangle_{\mathrm{w}}$ and $\lambda_{\mathrm{r}}=\frac{1}{N} \sum_{w=1}^{N}<\lambda_{\mathrm{Me}}>_{\mathrm{w}}$. Here $\mathrm{w}$ is a sequence number of weekly observation; $N$ is a total number of weekly observations. For ID137954 radiobeacon $N=106$. Deviations were recalculated into the distance units as the distances between two points on a sphere of $6371 \mathrm{~km}$ radius (mean radius of the Earth);

2) the radius of $C E P$ circumference in which get $50 \%$ of locations:

$$
C E P=0,59\left(\sigma_{\varphi}+\sigma_{\lambda}\right) \pm 3 \%,
$$

where $\sigma_{\varphi}, \sigma_{\lambda}$ are root-mean-square deviations of daily average coordinates $\left(<\varphi_{\mathrm{Me}}>_{\mathrm{w}},<\lambda_{\mathrm{Me}}>_{\mathrm{w}}\right)$, respectively;

3 ) the radius of $2 D R M S$ circumference in which get $95 \%$ of locations:

$$
2 D R M S=2 \sqrt{\sigma_{\varphi}^{2}+\sigma_{\lambda}^{2}} .
$$
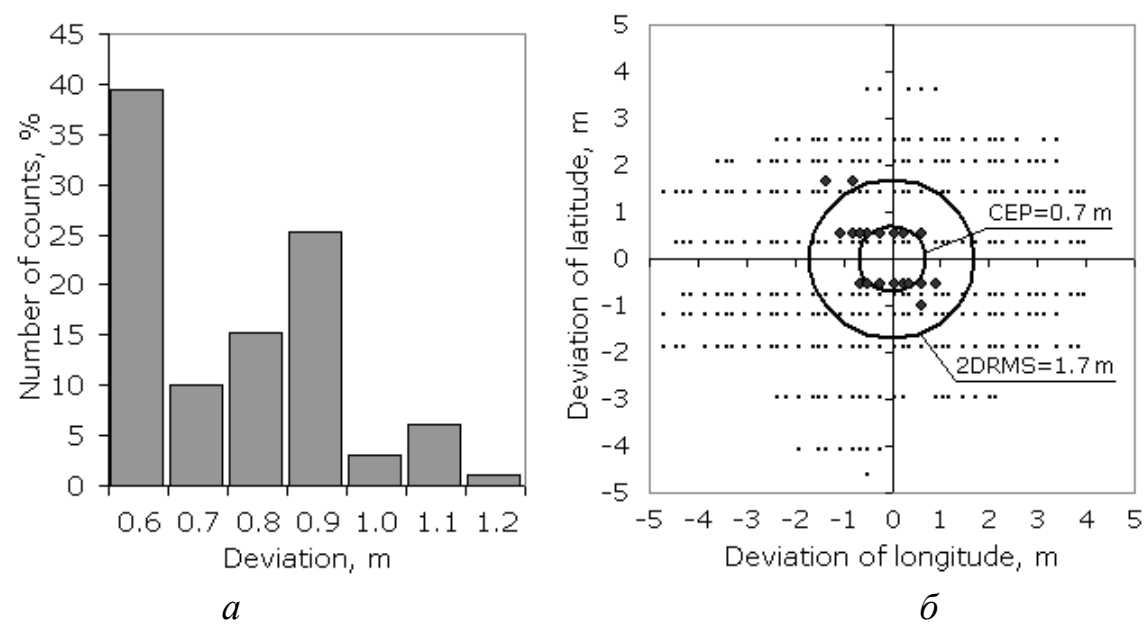

Fig. 1. Distributions of deviations between the radiobeacon positions calculated by mean daily coordinates, and a position calculated from the coordinates averaged over the entire observation period $a$; deviations of medians calculated by the data of each 5-minute measurement interval (black points), and mean daily (bold black points) values of latitude and longitude from the position calculated from the coordinates averaged over the entire observation period $-b$ 
Assessment results are shown in Fig. 1. From the distribution of deviations (Fig. 1, a) it can be seen that in $93 \%$ of measurements radiobeacon location was determined less than $1 \mathrm{~m}$ error. In Fig. $1, b$ the deviations of locations with $\left[\left(\varphi_{\mathrm{Me}}\right)_{k},\left(\lambda_{\mathrm{Me}}\right)_{k}\right]_{\mathrm{w}}$ and $\left(<\varphi_{\mathrm{Me}}>_{\mathrm{w}},<\lambda_{\mathrm{Me}}>_{\mathrm{w}}\right)$ coordinates from the position with $\left(\varphi_{\mathrm{r}}, \lambda_{\mathrm{r}}\right)$ ones are given. In the same figure the circumferences fallen in $50 \%$ $(C E P=0.7 \mathrm{~m})$ and $95 \%(2 D R M S=1.7 \mathrm{~m})$ of locations with $\left(\left\langle\varphi_{\mathrm{Me}}\right\rangle_{\mathrm{w}},\left\langle\lambda_{\mathrm{Me}_{\mathrm{e}}}\right\rangle_{\mathrm{w}}\right)$ coordinates are shown. The assessments of CEP and $2 D R M S$ are interrelated and based on the assumption of the error distribution normality [14], which is not always true. Nevertheless, these estimates are widely applied as indicators of navigation equipment use, and here they are given for convenience of comparison. The distribution of deviations should be considered as the most informative of the obtained positioning accuracy indicators (Fig. 1, $a$ ).

Estimations of quality of information transmission via the satellite communication channel. The most important radiobeacon characteristic as an operative monitoring tool is the quality of collected data transmission to users. Telemetry of iceST/40-Glacier radiobeacons is provided within the framework of Argos-2 satellite system. For a number of reasons, particularly due to the limited number of satellites which support the system, not all of the transmitted information becomes available to users. A number of the missed data can be judged by a distribution histogram of time intervals between the received measurements of median values of $\left[\left(\varphi_{\mathrm{Me}}\right)_{k},\left(\lambda_{\mathrm{Me}}\right)_{k}\right]$ ID137954 radiobeacon coordinates (Fig. 2) which, as was mentioned above, are transmitted with $5 \mathrm{~min}$ interval. It can be seen from the graph that the user received less than $50 \%$ of messages with a nominal interval. In total for 743 days of radiobeacon operation, $\sim 30 \%$ of such measurements were lost. Daily average coordinates $\left(\left\langle\varphi_{\mathrm{Me}}\right\rangle_{\mathrm{w}},\left\langle\lambda_{\mathrm{Me}}\right\rangle_{\mathrm{w}}\right)$, which are calculated in the data processing block of the radiobeacon according to all values of $\left[\left(\varphi_{\mathrm{Me}}\right)_{k},\left(\lambda_{\mathrm{Me}}\right)_{k}\right]$ and are transmitted within 19:00 - 22:00 period, were fully obtained - 106 weekly measurements over 743 days. Thus, due to the application of the above considered algorithm, the information omissions did not result neither in the loss of data on the radiobeacon position, nor in the positioning error increase.

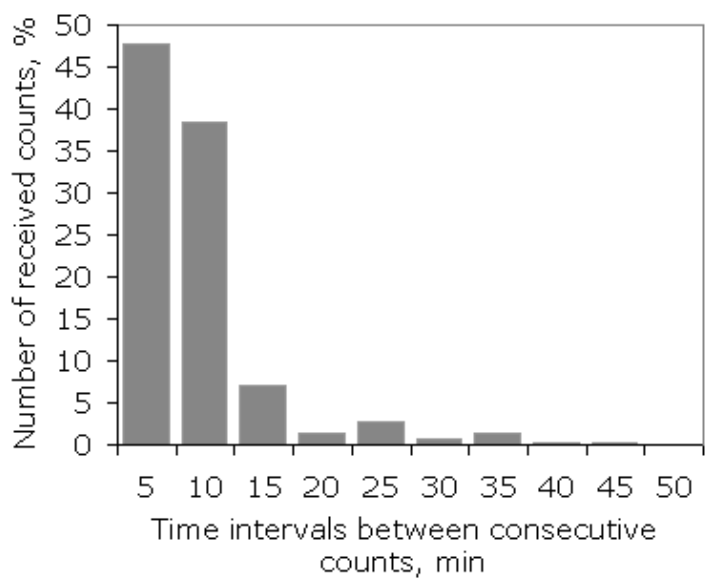

Fig. 2. Distribution of time intervals between the received samples of the median values of ID137954 satellite tracker coordinates calculated by each 5-min measurement interval 
Another situation also turned out to be possible. For instance, in ID137942 radiobeacon data from 14.08.2016 average coordinate values for this day were absent (were not received by the user), and it was possible to restore the location, although with a slightly larger error, by 5 min median readings.

The results of in situ experiments. Since May 2015, iceST/40-Glacier radiobeacons have been used for ice cover monitoring on the archipelagos of the Russian Federation Arctic zone. Over the next two years the observational network was supported by 12 radiobeacons, the operation period of four of them as for June 2017 exceeded 2 years. Some monitoring results obtained during this period are considered below.

In Fig. 3 on the left the trajectories of glaciers, calculated according to weekly daily average coordinates $\left.\left(<\varphi_{\mathrm{Me}}\right\rangle_{\mathrm{w}},\left\langle\lambda_{\mathrm{Me}}\right\rangle_{\mathrm{w}}\right)$ of ID137942, ID137943 and ID137953 radiobeacons, are given. The graphs are plotted in the path units and show the displacements of the radiobeacons from the points of their deployment. Markers on the trajectories indicate the locations calculated by the weekly average daily coordinates. Positive deviations along the ordinate axes correspond to the direction northern direction, negative - to the southern one; along the abscissa axes: positive - to the east, negative - to the west. For each radiobeacon there are given: the traveled path $S$ and the distance $D$ (on which the radiobeacon had displaced) calculated on the basis of data May 10, 2015 - June 4, 2017 period; the greatest velocity $V_{\text {wmax }}$; fluctuations of the velocity weekly values $\sigma_{V_{\mathrm{w}}}$.

In Fig. 3 on the right the time series of monthly distances covered by the radiobeacons $S_{\mathrm{m}}$ are shown by column diagrams, by Gantt charts - movement velocities $V_{\mathrm{w}}$ calculated by weekly daily average $\left(\left\langle\varphi_{\mathrm{Me}}\right\rangle_{\mathrm{w}},\left\langle\lambda_{\mathrm{Me}}\right\rangle_{\mathrm{w}}\right)$ coordinates. For ID137943 movement parameters were assessed by the trajectory on which the section of July 10 - September 25, 2016 with significant (failure) deviations was replaced by linearly interpolated one. On this trajectory section (shown in the graph by darker color) the glacier probably went round the rock formations that screened GPS receiver of the radiobeacon. This resulted in much greater uncertainty in the estimation of the coordinates.

According to ID137942 radiobeacon data, abnormally high velocity of movement was observed on October 16-23, 2016. The glacier displacement at $54.4 \mathrm{~m}$ over this week is probably due to its movement along the inclined part of underlying surface. Later, the characteristics of the glacier trajectory were similar to those observed earlier, and the data obtained on October 23, 2016 were not taken into account in the results given below.

For the entire period of observations, the most intensive was the glacier movement reconstructed according to the data of ID137953 radiobeacon. In 756 days the glacier shifted at $412 \mathrm{~m}$ with $432 \mathrm{~m}$ trajectory length. The largest displacement was recorded on June 19-26, 2016 and it was $9 \mathrm{~m}(\sim 130 \mathrm{~cm} /$ day $)$; the smallest one - on June 5-12, 2016 and made up $1.2 \mathrm{~m}$ ( $\sim 17 \mathrm{~cm} /$ day $)$. 


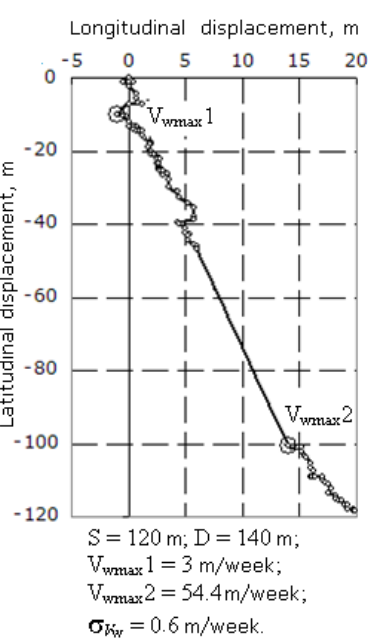

\section{$\underline{\text { ID137942 }}$}

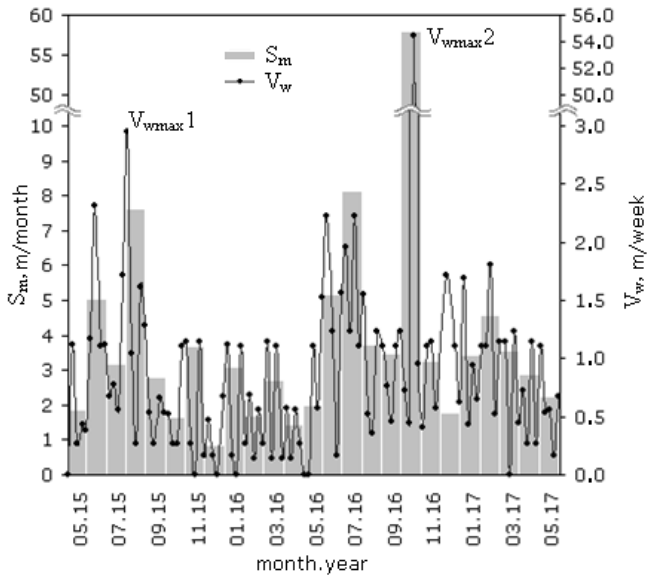

\section{$\underline{\text { ID } 137943}$}
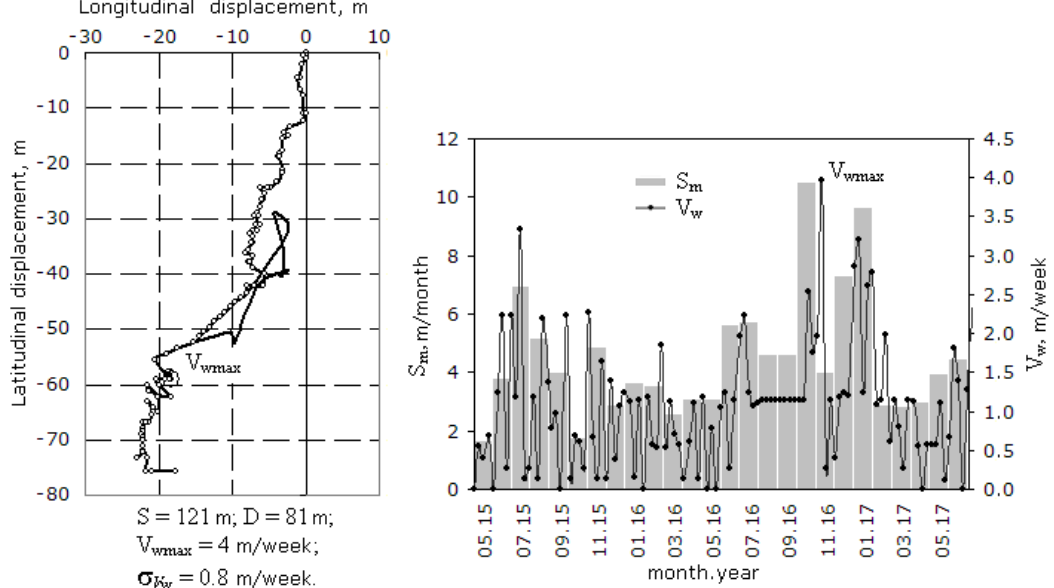

\section{$\underline{\text { ID } 137953}$}
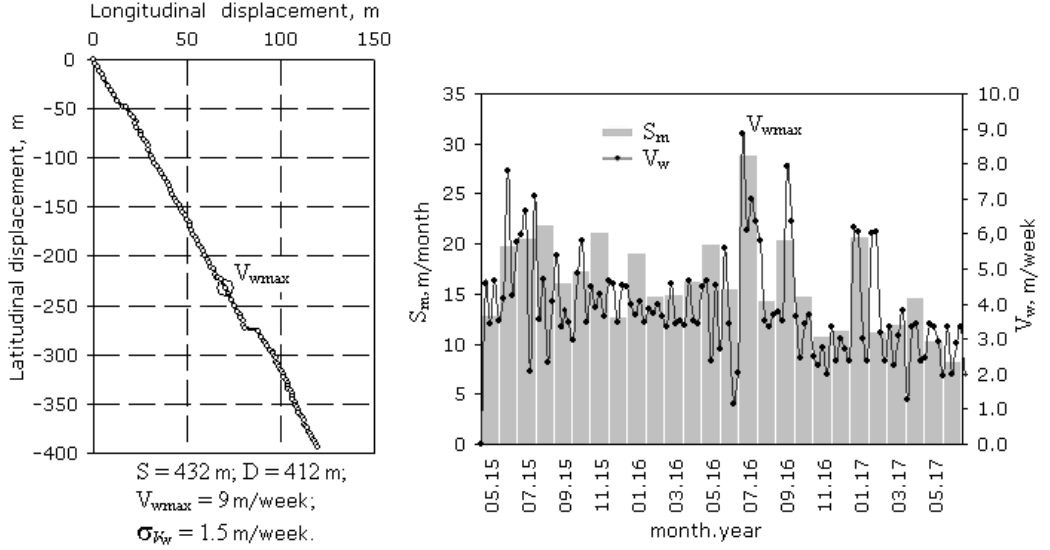

Fig. 3. Trajectories of glaciers (on the left); time series of $S_{m}$ monthly distances and $V_{w}$ velocity (on the right) calculated by weekly daily average coordinates of ID137942, ID137943 and ID137953 radiobeacons 
In addition to the location data, the information transmitted by radiobeacons also includes ice temperature measurements. The measurements with less than $0.1{ }^{\circ} \mathrm{C}$ error are carried out every Sunday at 18:00. From a comparison of time series of temperatures and motion velocities of glaciers, it can be concluded that seasonal temperature variation is much more closely related to the velocity fluctuations than to its average estimates.

Conclusion. In 2015-2017 iceST/40-Glacier radiobeacons developed in Marine Hydrophysical Institute of RAS and intended for glacier formation observations were tested on the archipelagos of the Russian Federation Arctic zone. Hardware and software solutions implemented in the radiobeacons were aimed at creating a relatively low-cost means of wide application, providing high reliability of coordinate measurements, prompt data delivery to users, long-term autonomy, resistance to the impact of affecting factors characteristic of the polar regions, simplicity of deployment technology. Field experiment results not just confirmed, but also largely surpassed the expected characteristics: the autonomous operation time of 4 of 12 radiobeacons exceeded 2 years; monitoring data were transmitted to users via the channels of Argos-2 satellite system almost in their entirety; location determination error in $93 \%$ of the measurements did not exceed $1 \mathrm{~m}$.

During the experiment, the initial purpose of which was to test the operability of radiobeacons, unique time series of measurements were obtained. This provides statistical estimation of glacier movement characteristics within a wide range of spatial-temporal scales.

The results of the analysis represent a creation of effective autonomous tool for glacier observations which can be regarded as an element of a reliable and economical system of long-term operational monitoring of ice conditions in the Arctic. Such a system will increase the safety of navigation and operation of oil platforms located on the Arctic shelf. Also it will provide the validation of data obtained by remote methods.

\section{REFERENCES}

1. Akimov, V.A., Kozlov, K.A. and Kosorukov, O.A., 2014. Sovremennye Problemy Arkticheskoy Zony Rossiyskoy Federatsii [Contemporary Problems of the Russian Federation Arctic Zone]. Moscow: VNII GOCHS, 308 p. (in Russian).

2. Govorushko, S.M., 2006. Ledniki i Ikh Znachenie dlya Chelovecheskoy Deyatel'nosti [Glaciers and their Importance for Human Activity]. Vestnik of the Far East Branch of the Russian Academy of Sciences, (6), pp. 60-70 (in Russian).

3. Paul, F., Winsvold, S.H., Kääb, A., Nagler, T. and Schwaizer, G., 2016. Glacier Remote Sensing Using Sentinel-2. Part II: Mapping Glacier Extents and Surface Facies, and Comparison to Landsat-8. Remote Sens., [e-journal] 8(7), 575. doi:10.3390/rs8070575

4. Pope, A. and Rees, W.G., 2014. Impact of Spatial, Spectral, and Radiometric Properties of Multispectral Imagers on Glacier Surface Classification. Remote Sens. Environ., [e-journal] 141, pp. 1-13. https://doi.org/10.1016/j.rse.2013.08.028

5. Kotlyakov, V.M., Khromova, T.E., Nosenko, G.A., Popova, V.V., Chernova, L.P., Muravev, A.Ya., Rototaeva, O.V., Nikitin, S.A. and Zverkova, N.M., 2015. Sovremennye Izmeneniya Lednikov Gornykh Rayonov Rossii [Recent Glacier Changes in Mountain Regions of Russia]. Moscow: KMK Scientific Press Ltd., 287 p. (in Russian).

6. Bolch, T., 2011. Assessment of Cryospheric Variations in Different Climatic Regimes and Their Impacts Using Geomatics: Habilitation. Dresden: Technische Universität Dresden, 268 p. Available at:https://www.researchgate.net/publication/272793711_Assessment_of_cryospheric_variations_in_d ifferent_climatic_regimes_and_their_impacts_using_geomatics [Accessed 20 September 2017]. 
7. Karelin, A.V. and Nagovitsyna, N.V., 2014. Bazovye Elementy i Metrologicheskie Aspekty Validatsionnykh Rabot [Basic Elements and Metrological Aspects of Validation Works]. Cosmonautics and Rocket Engineering, (5), pp. 101-107 (in Russian).

8. Astashkin, A.A., Komissarova, I.N., Markelova, T.S., Nagovitsyna, N.V., Novikova, N.P., Tverdokhlebova, Ye.M. and Ustinova, M.V., 2015. Informatsionnoe Obespechenie Issledovaniya Arkticheskogo Regiona s Ispol'zovaniem Gidrometeorologicheskoy Kosmicheskoy Sistemy «Arktika-M» [Information Maintenance of Research in the Arctic Region Using the «Arktika-M» Hydrometeorological Space System]. Cosmonautics and Rocket Engineering, (6), pp. 11-19 (in Russian).

9. King, M., Watson, C., Coleman, R., Sprent, A., Guichard, A. and Williams, G., 2001. A Low Cost GPS System for Ice Movement Studies. 18 p. Available at: https://www.latitude.aq/publications/pdf/low_cost_gps_system_2001.pdf [Accessed 20 September 2017].

10. den Ouden, M.A.G., Reijmer, C.H., Pohjola, V., van de Wal, R.S.W., Oerlemans, J. and Boot, W., 2010. Stand-alone single-frequency GPS ice velocity observations on Nordenskiöldbreen, Svalbard. The Cryosphere, [e-journal] 4, pp. 593-604. doi:10.5194/tc-4-593-2010

11. Marlin-Yug, 2017. Available at: http://marlin-yug.com/ru/home [Accessed: 20 September 2017].

12. Semenov, S.M., ed., 2012. Metody Otsenki Posledstviy Izmeneniya Klimata dlya Fizicheskikh i Biologicheskikh Sistem [Methods for Assessing the Consequences of Climate Change on Physical and Biological Systems]. Moscow: Planeta, pp. 360-399 (in Russian).

13. ARGOS, 2017. Available at: http://www.argos-system.org [Accessed 20 September 2017].

14. Zandbergen, P.A., 2008. Positional Accuracy of Spatial Data: Non-Normal Distributions and a Critique of the National Standard for Spatial Data Accuracy. Transactions in GIS, [ejournal] 12(1), pp. 103-130. doi:10.1111/j.1467-9671.2008.01088.x

\section{About the authors:}

Sergey V. Motyzhev - Senior Research Associate, Head of the Scientific Direction of Instrumentation, FSBSI MHI (2, Kapitanskaya Str., Sevastopol, 299011, Russian Federation), Dr.Sci. (Tech.), ORCID ID: 0000-0002-8438-2602, motyzhev@marlin-yug.com

Aleksey P. Tolstosheev - Senior Research Associate, Department of Innovative Technologies, FSBSI MHI (2, Kapitanskaya Str., Sevastopol, 299011, Russian Federation), Ph.D. (Tech.), ORCID ID: 0000-0002-0771-0879, tolstosheev@ marlin-yug.com

Evgeniy G. Lunev - Research Associate, Department of Innovative Technologies, FSBSI MHI (2, Kapitanskaya Str., Sevastopol, 299011, Russian Federation), Ph.D. (Tech.), ORCID ID: 0000-00027138-3024,lunev@ marlin-yug.com

Aleksandr L. Salman - Director General, ES-PAS Ltd (Moscow, Russia), a.salman@es-pas.com

\section{Contribution of the co-authors:}

Sergey V. Motyzhev - general scientific supervision of the research, the development and scientific substantiation of the research concept, formulation and statement of the problem, formulation of conclusions, editing and supplementing the text of the article

Aleksey P. Tolstosheev - analysis of materials in domestic and foreign sources on the research methods, development of methods and carrying out the experimental studies, qualitative and quantitative analysis of the research results and preparation of initial conclusions, preparation of the article text

Evgeniy G. Lunev - development of research tools, development of methods and carrying out the experimental studies, development and debugging of the computer program for solving the problem, qualitative and quantitative analysis of the research results and preparation of initial conclusions, editing and supplementing the article text

Aleksandr L. Salman - statement of the general problem of the research, formulation of goals and objectives of the research, financial support, editing and completing the article text

All the authors have read and approved the final manuscript.

The authors declare that they have no conflict of interest. 